\title{
Peripheral Neuropathy with Ataxia in Childhood as a Result of the G8363A Mutation in Mitochondrial DNA
}

\author{
MERCEDES PINEDA, ABELARDO SOLANO, RAFAEL ARTUCH, ANTONIO L. ANDREU, \\ ANA PLAYAN, MARIA A. VILASECA, JAIME COLOMER, PAZ BRIONES, \\ JORDI CASADEMONT, AND JULIO MONTOYA
}

Serveis de Neuropediatria [M.P., R.A., M.A.V., J.Co., J.Ca.], Bioquímica i Medicina Interna, Unitat Integrada, Clinic-Hospital Sant Joan de Déu, Barcelona 08950, Spain; Departamento de Bioquímica y Biología Molecular y Celular [A.S., A. P, J.M.], Universidad de Zaragoza, Zaragoza 50013, Spain; Centre d'Investigació en Bioquímica i Biología Molecular [A.L.A.], University Hospital Vall d'Hebron, Barcelona, 08035 Spain; and Institut de Bioquímica Clínica-CSIC [P.B.], Barcelona 08280, Spain

\begin{abstract}
Peripheral neuropathy has been identified in children with mitochondrial encephalomyopathies but not as a main clinical landmark. Here we report the clinical, electrophysiologic, biochemical, and genetic findings in a family who harbors the G8363A mutation in the tRNALys gene of mitochondrial DNA. Affected individuals presented with peripheral neuropathy and ataxia as the main clinical sign. Additional involvement included muscle weakness and multiple lipomatosis. Other common clinical characteristics associated with the G8363A mutation, such as cardiomyopathy and myoclonus epilepsy, were not observed.
\end{abstract}

\section{ABSTRACT}

These findings suggest that a mitochondrial disease should be considered in the differential diagnosis of children with heredoataxic syndrome and peripheral neuropathy of unknown origin. (Pediatr Res 56: 55-59, 2004)

\author{
Abbreviations \\ MRI, magnetic resonance imaging \\ mtDNA, mitochondrial DNA \\ RFLP, restriction fragment length polymorphism
}

Progressive sensory axonal neuropathy is a frequent finding in heredoataxic disorders, particularly in Friedreich's ataxia $(1,2)$. Moreover, it has also been reported in adult patients with mitochondrial encephalomyopathy (3-5). However, peripheral neuropathy is barely seen in children with mitochondrial disease (6). Here we report clinical, electrophysiologic, biochemical, and genetic data in a kindred spanning four generations who harbor the G8363A mutation in the tRNALys gene of mitochondrial DNA (mtDNA). The clinical presentation of the G8363A mutation in this family has remarkable peculiarities when compared with the eight previously reported kindreds. Although the G8363A mutation often presents with cardiomyopathy and myoclonus epilepsy, the main clinical presentation in our family was the presence of severe sensory neuropathy

Received June 27, 2003; accepted December 3, 2003

Correspondence: Mercedes Pineda, M.D., Ph.D., S. Neuropediatria, Hospital Sant Joan de Déu, Passeig St., Joan de Déu n 2, 08950 Esplugues, Barcelona, Spain; e-mail: pineda@hsjdbcn.org

This work was supported by grants from Diputación General de Aragon (P032-2000), Spanish Ministry of Health (FIS 98-2000/0049), and Spanish Network of Mitochondrial Disorders and Ataxias (G03-011 and G03-056). A.S. was a recipient of a fellowship from the Mexican Government (CONACYT-121963).

DOI: 10.1203/01.PDR.0000130475.20571.98 with ataxia. It is interesting that the onset of the heredoataxic presentation was for most patients before age 10, and some individuals' disease was even misdiagnosed as Friedreich's ataxia. The characteristics of this family suggest that mitochondrial disease should be ruled out in children who present with heredoataxic syndromes and peripheral neuropathy of unknown origin.

\section{METHODS}

\section{Clinical Presentations}

Figure $1 A$ shows the pedigree of the family.

Individual IV:1. This girl was born after a normal pregnancy and had a normal neonatal period and normal development. At age 4, during a viral infection, she had a febrile convulsion. EEG showed normal background and generalized paroxysmal spike and waves discharges after photostimulation. At age 6, parents noted an odd clumsy hodge performance and low school level. Neurologic examination performed at age 9 showed gait ataxia, pes cavus, hyporeflexia of the lower extremities, and slight dysmetria. Normal sensibility for modalities was present. Fundus oculi and cardiologic examination were normal. The Wechsler Intelligence Scale for Children 

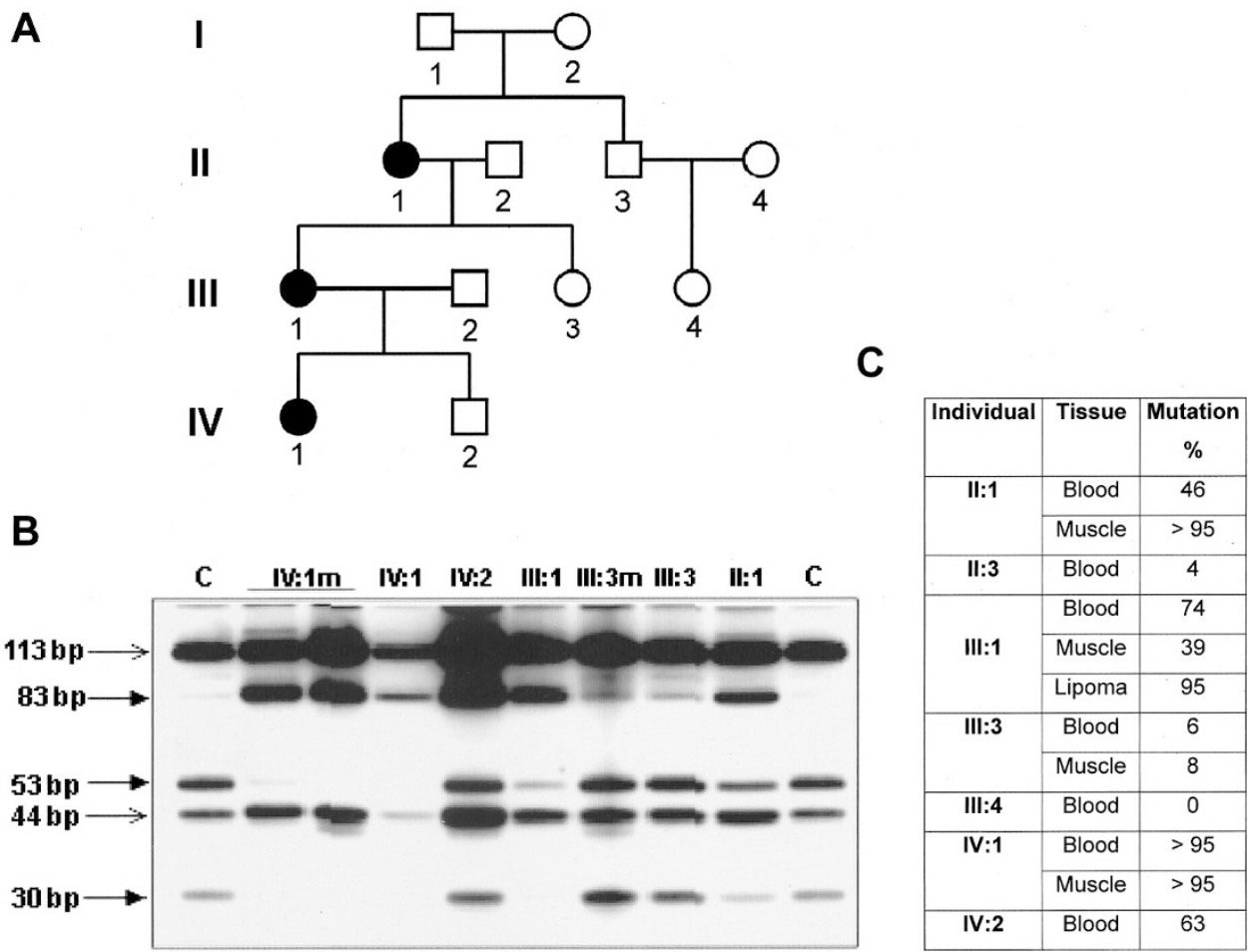

Figure 1. Pedigree and RFLP analysis of the G8363A affected family. (A) Family tree; $\boldsymbol{\bullet}$, women in this family affected with muscular weakness, severe neuropathy, and/or presence of lipoma. (B) RFLP analysis. A 240-bp amplification product (8341-8582) is cut by Hph I into four fragments of 113, 53, 44, and $30 \mathrm{bp}$. The G8363A mutation abolishes one of the restriction sites for Hph I, reducing the number of fragments to three (113, 83, and $44 \mathrm{bp})$. For estimating the percentage of mutant mtDNAs, $\left[\alpha-{ }^{32} \mathrm{P}\right] \mathrm{dCTP}$ was added in the last PCR cycle and digestion products were electrophoresed through a $10 \%$ nondenaturing polyacrylamide gel. (C) Percentages of the mutation in different tissues of all members of the family analyzed.

revealed an IQ of 80 . A brain magnetic resonance imaging (MRI) scan performed at age 9 showed diffuse leukodystrophy of the periventricular white matter of the occipital regions. Normal visual evoked potentials and electroretinogram (ERNG) were present. Brain stem auditory evoked potentials showed low amplitude. Somatosensory evoked potentials were abnormal with very low amplitude. Results of the electrophysiologic studies are shown in Table 1. At age 16, the patient presented with nystagmus, slight ataxia, and severe distal muscle weakness. A repeat brain MRI with spectroscopy showed cerebellar atrophy with normal cerebral white matter. Renal, cardiologic, and endocrinologic functions were normal. Laboratory tests showed increased blood lactate $(2.6 \mathrm{mM})$, and polarographic measurements showed decreased oxygen consumption in lymphocytes when incubated with pyruvate plus

Table 1. Neurophysiologic studies

\begin{tabular}{|c|c|c|c|}
\hline & \multicolumn{2}{|c|}{ Individual } & \multirow[b]{2}{*}{ Normal values } \\
\hline & III:I & IV:I & \\
\hline \multicolumn{4}{|l|}{ N. Suralis } \\
\hline $\mathrm{CV} \mathrm{m} / \mathrm{s}$ & 0 & 0 & $56.7 \pm 53$ \\
\hline SNAP $(\mu \mathrm{V})$ & NR & NR & $8.4 \pm 2.3$ \\
\hline \multicolumn{4}{|l|}{ N. Peroneus } \\
\hline $\mathrm{CV} \mathrm{m} / \mathrm{s}$ & 34.4 & 40.9 & $55.1 \pm 5.5$ \\
\hline CMAP (mV) & 0.68 & 2.39 & $7.9 \pm 3.74$ \\
\hline EMG & $\begin{array}{c}\text { Neurogenic } \\
\text { pattern }\end{array}$ & $\begin{array}{c}\text { Neurogenic } \\
\text { pattern }\end{array}$ & \\
\hline
\end{tabular}

$\mathrm{CV}$, conduction velocities; SNAP, sensory nerve action potential; CMAP, motor nerve action potential; NR, no response; EMG, electromyograph. malate $\left(1.6 \mathrm{nmol}\right.$ oxygen $\cdot \min ^{-1} \cdot \mathrm{mg}$ protein ${ }^{-1}$; reference values, $2.3-7.1)$ or glutamate $\left(2.3 \mathrm{nmol}\right.$ oxygen $\cdot \mathrm{min}^{-1} \cdot \mathrm{mg}$ protein $^{-1}$; reference values, $2.6-7.0$ ).

Individual IV:2. This 18-y-old man was asymptomatic. Clinical examination and laboratory and electrophysiologic studies were normal.

Individual III:1. This 38-y-old female noticed progressive weakness and unsteady gait at age 14, when her disease was misdiagnosed as Friedreich's ataxia. At age 28, she developed a horse collar lipoma. At age 32, clinical examination showed severe sensory neuropathy with loss of vibratory and position sensation and conserved nociception. Areflexia, ataxia, slight dysmetria, dysarthria, and Romberg sign were present. Electrophysiologic studies are shown in (Table 1). Cardiac, renal, and endocrinologic functions were normal. A brain MRI with spectroscopy showed bilateral basal ganglia hyperintensities of T2 signal with increased lactate and cerebellar atrophy. The patient has developed progressive reduction of visual acuity in the past $2 \mathrm{y}$, with bilateral optic disc pallor and a lipoma of the cervical region (Fig. 2A). Pes cavus with important distal muscular amyotrophy and weakness makes it nearly impossible for her to walk unaided. This year, the first symptoms of cardiomyopathy have recently appeared. Laboratory investigations showed increased blood lactate $(2.9 \mathrm{mM})$. Polarographic studies showed slightly abnormal oxygen consumption in lymphocytes incubated with pyruvate plus malate $(2.3 \mathrm{nmol}$ oxygen $\cdot \min ^{-1} \cdot \mathrm{mg}$ protein $\left.{ }^{-1}\right)$ or glutamate $(2.4 \mathrm{nmol}$ oxygen $\cdot$ $\min ^{-1} \cdot \operatorname{mg}$ protein $^{-1}$ ). 

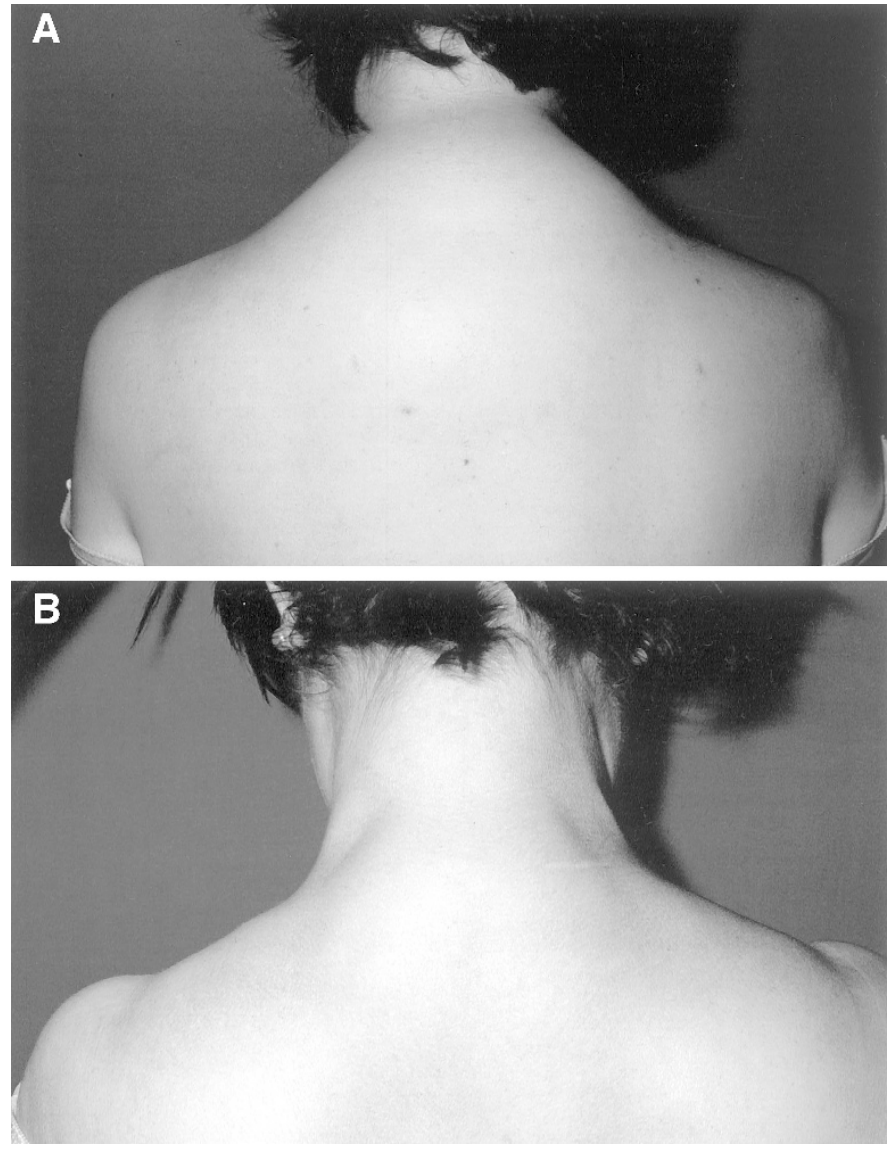

Figure 2. (A) Lipoma of individual III:1. (B) Lipoma of individual II:1.

Individual III:3. This patient was clinically asymptomatic at age $28 \mathrm{y}$. Laboratory and electrophysiologic studies were normal.

Individual II:1. Neurologic examination was normal at age 63. At age 28, the patient developed a large lipoma around the neck, which required surgery twice (Fig. 2B). Laboratory and electrophysiologic studies were normal.

Individual II:3. Neurologic examination was normal at age 60. However, the patient also presented with a lipoma in the neck and cervical region.

\section{Biochemical Studies}

Lactate and pyruvate were analyzed according to previously reported methods (7). Oxygen consumption measurements were performed in digitonine-permeabilized lymphocytes using a Clark-type oxygen electrode as described (8). Histochemical and biochemical determinations in muscle samples were performed by standard procedures $(9-12)$.

\section{Genetic Studies}

Blood and skeletal muscle were obtained for mtDNA analysis from all patients. In addition, adipose tissue obtained from the removed lipoma was obtained from individual III: 1. Total DNA was isolated from blood and muscle by standard procedures, and the following point mutations in mtDNA were ruled out by restriction fragment length polymorphism (RFLP) anal- ysis: A8344G, T8356C, A3243G, T3271C, and T8993G. As RFLP results were negative, the mtDNA tRNALys gene was sequenced by standard procedures. Amounts of mutated G8363A genomes were assessed by RFLP analysis using the restriction enzyme Hph $I$ (13).

Samples of patients and control subjects were obtained in accordance with the 2000 revised Helsinki Declaration of 1975. Informed consent was obtained from the family. The Institutional Review Board and Ethical Committee of the Sant Joan de Déu Hospital approved the study.

\section{RESULTS}

Skeletal muscle biopsies. Histopathologic studies revealed the presence of scattered ragged-red fibers in individual II:1. The study of the muscle of individual III:1 showed abundant COX-negative ragged-red fibers, with neurogenic atrophy. Enzyme activities of the respiratory chain were performed in frozen muscle of individuals IV:1 and II: 1 and in fibroblasts of individuals IV:2 and II:1 with normal results. The studies of a fresh muscle biopsy of individual III:I showed deficient pyruvate and malate oxidation and partial defect of complex I. A fresh muscle biopsy of the asymptomatic individual III:3 also showed deficient pyruvate oxidation and ATP production but normal enzyme activities of the respiratory chain. Nerve biopsies were not available.

Genetic studies. Sequencing analysis of muscle DNA from individual IV:1 revealed the presence of the G8363A point mutation in the mtDNA tRNALys gene. Figure $1 B$ shows the RFLP analysis of the mutation in most of the individuals studied. Mutation load ranged from $6 \%$ in individual III:3 to $>95 \%$ in blood and muscle from individual IV: 1 and muscle from II: 1 and in the only lipoma sample that was available for the study (from individual III:1; Fig. 1C).

\section{DISCUSSION}

This family developed increasing severe sensory neuropathy and heredoataxic syndrome since childhood. Mixed peripheral neuropathy has frequently been reported in children with mitochondrial disorders. However, sensory ataxic neuropathy has rarely been described as a predominant sign. The electrophysiologic studies of the peripheral nerves were similar to those of the Friedreich ataxia neuropathy (2), with absence of sensory nerve action potentials. However, our patients also showed a slight amplitude reduction in compound motor action potentials, mild slowing of conduction velocities, and prolonged distal latencies, indicating axonal motor and sensory neuropathy. Electromyograph revealed a neurogenic pattern in distal muscles of the lower limbs without myopathic changes in individuals III:1 and IV:1. This differs from the characteristic pattern of Friedreich's ataxia; although initially misdiagnosed, it was also excluded by clinical follow-up and genetic studies. Otherwise, Friedreich's ataxia and vitamin E deficiency are recessive disorders, and our cases are quasi-dominant. Polyneuropathy (mixed axonal and demyelinating sensory and motor polyneuropathy) has been described with various clinical phenotypes in mitochondrial disorders, but only few of these studies have been correlated with the mitochondrial genotype. 
Table 2. G8363A reported families

\begin{tabular}{|c|c|c|c|c|c|c|c|c|c|}
\hline & \multicolumn{2}{|c|}{ Santorelli (13) } & \multicolumn{2}{|c|}{ Ozawa (15) } & \multirow{2}{*}{$\begin{array}{c}\text { Arenas } \\
\text { (18) }\end{array}$} & \multirow{2}{*}{$\begin{array}{c}\text { Casali } \\
(19)\end{array}$} & \multirow{2}{*}{$\begin{array}{c}\text { Shtilbans } \\
(16)\end{array}$} & \multirow{2}{*}{$\begin{array}{l}\text { Graf } \\
(17)\end{array}$} & \multirow{2}{*}{$\begin{array}{l}\text { Our } \\
\text { case }\end{array}$} \\
\hline & A & $\mathrm{B}$ & $\mathrm{A}$ & $\mathrm{B}$ & & & & & \\
\hline Cardiomyopathy & +++ & +++ & ++ & & & + & & & + \\
\hline Hearing loss & ++ & +++ & & & + & + & + & & \\
\hline Ophthalmoparesis & ++ & & & & & + & + & & \\
\hline Lipoma & & + & & & & ++ & & & ++ \\
\hline Myoclonic epilepsy & & & ++ & ++ & ++ & + & + & + & \\
\hline Ataxia & ++ & ++ & & ++ & +++ & ++ & & & +++ \\
\hline Muscle weakness & ++ & + & + & + & & & & & ++ \\
\hline Peripheral neuropathy & + & ++ & & & ++ & ++ & ++ & & +++ \\
\hline Cognitive/motor regression & + & + & & + & & & ++ & +++ & \\
\hline Autism & & & & & & & & +++ & \\
\hline
\end{tabular}

Phenotype comparison between the different families reported to have the G8363A mutation. Symptoms are classified as + , mild;,++ moderate; +++ , severe.

One of the exceptions to this rule is the NARP syndrome (neurogenic weakness, ataxia, and retinitis pigmentosa), in which the presence of axonal neuropathy is a major diagnostic criteria (14).

Peripheral neuropathy and ataxia seem to be one of the features present in patients who harbor the G8363A mutation. This mutation was originally reported to be associated with cardiomyopathy and hearing loss (13) and subsequently in two Japanese families who presented myoclonus epilepsy and lipomas (15). In recent work, the mutation was identified as associated with Leigh syndrome $(16,17)$. Brain MRI in individual IV:1 showed leukodystrophy in periventricular white matter. However, the follow-up MRI years after showed only cerebellar atrophy. A possible explanation is that the patient had dysmyelination in the first MRI, and at present the patient shows normal white matter. Brain MRI with spectroscopy in individual III:1 showed bilateral hyperintensities of T2 signal with increased lactate in the basal ganglia and cerebellar atrophy.

Table 2 shows the clinical presentation of G8363A patients described to date. It is interesting that ataxia and peripheral neuropathy seem to be common in patients who harbor this molecular defect. However, other presentations such as cardiomyopathy and myoclonus epilepsy can be the major landmark of the G8363A mutation. There is a general agreement that factors other than the mutation itself could account for the presentation of the genotype of point mutations in mtDNA, and, when comparing the clinical phenotypes of G8363A patients, those from the Mediterranean area (18,19 and our family) present with a phenotype dominated by peripheral neuropathy.

Another remarkable finding is the presence of lipomas in some of these patients. Despite the wide clinical presentation of point mutations in mtDNA, the presence of lipomas associated with mtDNA point mutations has been reported exclusively in patients who harbor point mutations in the tRNALys gene, suggesting that some mtDNA genes have a "tissue specific" function (20). This observation has an important consequence from a diagnostic point of view, as the presence of maternally inherited lipomas accompanied with neurologic signs is almost "pathognomonic" of a mtDNA point mutation in the tRNALys gene. Recently, lipomas, sensory neuropathy, and mitochondrial diabetes have also been described to be associated with a tRNA mutation at position 3271 (21).

Clinical diagnosis of mitochondrial disorders requires a precise study of the clinical phenotypes. Especially in children, the association of different syndromes with the same mutation, phenotypic variation, and the association of different mutations with the same syndrome and genetic heterogeneity further complicates the possibility of diagnosis and classification. We conclude that a mitochondrial origin has to be investigated by searching mitochondrial mutations in clinical forms that resemble Friedreich's ataxia with negative genetic markers, as well as other forms of peripheral sensory neuropathies in childhood of unknown origin.

\section{REFERENCES}

1. Harding AE 1993 Clinical features and classification of inherited ataxias. Adv Neurol $61: 1-14$

2. Subramony SH 1995 Clinical aspects of hereditary ataxias. J Child Neurol 10:353362

3. Yiannikas C, McLeod JG, Pollard JD, Baverstock J 1986 Peripheral neuropathy associated with mitochondrial myopathy. Ann Neurol 20:249-257

4. Mizusawa H, Ohkoshi N, Watanabe M, Kanazawa I 1991 Peripheral neuropathy of mitochondrial myopathies. Rev Neurol (Paris) 147:501-507

5. Van Domburg PHMF, Gabreëls-Festen AAWM, Gabreëls FM, de Coo R, Ruitenbeek W, Wesseling P, ter Laak H 1996 Mitochondrial cytopathy presenting as hereditary sensory neuropathy with progressive external ophthalmoplegia, ataxia, and fatal myoclonic epileptic status. Brain 119:997-1010

6. Ouvrier RA, McLeod JGJ, Pollard JD 1999 Peripheral Neuropathy in Childhood, 2nd Ed. Raven Press, New York, pp 188

7. Artuch R, Vilaseca MA, Farré C, Ramón F 1995 Determination of lactate, pyruvate, $\beta$-hydroxybutyrate and acetoacetate with a centrifugal analyser. Eur J Clin Chem Clin Biochem 33:529-533

8. Artuch R, Colomé C, Playán A, Alcaine MJ, Briones P, Montoya J, Vilaseca MA, Pineda M 2000 Oxygen consumption measurement in lymphocytes for the diagnosis of paediatric patients with oxidative phosphorylation diseases. Clin Biochem 33:481485

9. Fischer JC, Ruitenbeek W, Berden JÁ, Trijbels JM, Veerkamp JH, Stadhouders AM, Sengers RC, Janssen AJ 1985 Differential investigation of the capacity of succinate oxidation in human skeletal muscle. Clin Chim Acta 153:23-36

10. Rustin P, Chretien D, Bourgeron T, Gérard B, Rötig A, Saudubray JM, Munnich A 1994 Biochemical and molecular investigations in respiratory chain deficiencies. Clin Chim Acta 228:35-51

11. Birch-Machin MA, Briggs HL, Saborido AA, Bindoff LA, Turnbull DM 1994 An evaluation of the measurement of the activities of complexes I-IV in the respiratory chain of human skeletal muscle mitochondria. Biochem Med Metab Biol 51:35-42

12. Rubio-Gozalbo ME, Sengers RCA, Trijbels JMF, Doesburg WH, Janssen AJM, Verbeek ALM, Smeitink JAM 2000 A prognostic index as diagnostic strategy in children suspected of a mitochondropathy. Neuropediatrics 32:114-121

13. Santorelli FM, Mak SC, El-Schahawi M, Casali C, Shanske S, Baram TZ, Madrid RE, DiMauro S 1996 Maternally inherited cardiomyopathy and hearing loss associated with a novel mutation in the mitochondrial tRNA(Lys) gene (G8363A). Am J Hum Genet 58:993-939

14. Holt IJ, Harding AE, Petty RKH, Morgan-Hughes JA 1990 A new mitochondrial disease associated with mitochondrial DNA heteroplasmy. Am J Med Genet 46:428433 
15. Ozawa M, Nishino I, Nonaka I, Goto YI 1997 Myoclonus epilepsy associated with ragged-red fibers: a G-to-A mutation at nucleotide pair 8363 in mitochondrial tRNA(Lys) in two families. Muscle Nerve 20:271-278

16. Shtilbans A, Shanske S, Goodman S, Sue CM, Bruno C, Johnson TL, Lava NS, Wahed N, DiMauro S 2000 G8363A Mutation in the mitochondrial DNA transfer ribonucleic acid gene: another cause of Leigh Syndrome. J Child Neurol 15:759761

17. Graf W, MarinGarcia J, Gao HG, Pizzo S, Naviaux RK, Markusic D, Barshop BA, Courchesne E, Haas RH 2000 Autism associated with the mitochondrial DNA G8363A transfer RNA(Lys) mutation. J Child Neurol 15:357-361

18. Arenas J, Campos Y, Bornstein B, Ribacoba R, Martin MA, Rubio JC, Santorelli FM, Zeviani M, DiMauro S, Garesse R 1999 A double mutation (A8296G and G8363A) in the mitochondrial DNA tRNA (Lys) gene associated with myoclonus epilepsy with ragged-red fibers. Neurology 52:377-382

19. Casali C, Fabrizi GM, Santorelli FM, Colazza G, Villanova M, Dotti MT, Cavallaro T, Cardaioli E, Battisti C, Manneschi L, DiGennaro GC, Fortini D, Spadaro M, Morocutti C, Federico A 1999 Mitochondrial G8363A mutation presenting as cerebellar ataxia and lipomas in an Italian family. Neurology 52:1103-1104

20. Gamez J, Playán A, Andreu AL, Bruno C, Navarro C, Cervera C, Arbós MA, Schwartz S, Enriquez JA, Montoya J 1998 Familial multiple symmetric lipomatosis associated with the A8344G mutation of mitochondrial DNA. Neurology 51:258-260 21. Suzuki Y, Tsukuda K, Taniyama M, Atsumi Y, Matsuoka K, Oka Y 2002 Lipoma and sensory neuropathy in mitochondrial diabetes associated with tRNA mutation at position 3271. Diabetes Care 25:407-408 